\title{
Relationship of mammographic densities to breast cancer risk
}

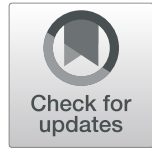

\author{
Engy A. Ali ${ }^{*}$ and Mariam Raafat
}

\begin{abstract}
Background: Our goal was to find out the relation between mammographic densities and cancer of the breast according to the recent ACR classification. From the medical records of Kasereliny Hospital, 49,409 women were subjected to digital mammography for screening, of which 1500 breast cancer cases were collected. The mammographic categories of breast density were ACR-A, B, C, and D, which were detected by two senior radiologists. All radiological classifications were made using both standard mammographic views bilaterally. Twosided tests of statistical significance were represented by all the $P$ values.

Results: From 2014 to 2019, 49,409 women came for digital mammographic screening, their age ranges between 40 and 65 , and all of them are included in the study. One thousand cases of breast cancer cases were radiologically and pathologically diagnosed. Different densities were arranged in descending pattern depending on the frequency of positive cases: D (13.7\%), C (3.3\%), B (2.7\%), A (2.2\%). There is positive significant risk ratio among every higher mammographic density in comparison to the lower density.

Conclusion: Our study results show that the risk of breast cancer is in close relation to the mammographic breast density.

Keywords: Mammography, Breast cancer, Breast mammographic density
\end{abstract}

\section{Background}

Screening in breast cancer is of great value in detecting asymptomatic cancer resulting in less invasive treatments and better outcome too as it will be discovered in its early stage before tumor progresses. Rules for the category of women which should be screened, how often, and by which imaging modality should be well-known [1].

Mammography is still the best recommended imaging tool for screening of breast cancer in all women which in turn depends on a common decision between the female and her clinician depending on the risk factors and competing co-morbidities [1].

Breast cancer risk is in close relation with increasing mammographic breast density. Breast in the

\footnotetext{
* Correspondence: drengyali78@gmail.com

Diagnostic and Intervention Radiology Department (Women's Imaging Unit), Kasr El-Ainy Hospital, Cairo University, Kasr Al-Ainy, El-Manial, Cairo 11956, Egypt
}

mammogram appears as a reflection of both the amount of fat and epithelial and connective tissues together. On mammogram, fat is represented by radiolucent areas, and the non-radiolucent areas related to the glandular and fibrous tissues. Women who have increased breast breast density [1].

Annual mammography as well as dynamic MRI is recommended in screening high-risk breast cancer women; ultrasound is recommended only when there are contraindications to MRI. Those with intermediate risk should average risk, annual mammography is enough [2].

The current work had presented an update analysis of the frequency of breast cancer in correlation to the type of breast density in the Egyptian female population. The study involved a large proportion of women $(n=49,409)$ whether subjected to screening or diagnostic 
mammograms. To our knowledge, there was no comparable study with the inclusion of such large sample size and discussed the risk of breast cancer in Egypt.

\section{Methods}

\section{Patients}

Our study included 49,409 women outreached for screening by digital mammography. Their data were collected from the medical records of Kasereliny Hospital radiology department in the period from January 2014 to December 2019.

\section{Inclusion criteria}

Asymptomatic females above the age of 40 years who are eligible for screening mammography

\section{Exclusion criteria}

- Mammographic contradiction, e.g., pregnant women

- Women under 40 years, where US is the modality of choice

All patients were submitted to the following:

- Demographic and clinical data collection Including patient's age, name, phone number, marital status, number of offsprings, residence, diagnosis, duration of illness, family history, and past history

\section{Imaging procedure}

All cases did digital mammography.

\section{Equipments}

- Mammographic examination was performed using the digital mammography system (Senographe 2000 D, GE, USA).

\section{Technique of full-field digital mammography}

- Standard views of craniocaudal and mediolateraloblique and craniocaudal were taken for all patients.

\section{Image analysis and interpretation of mammography}

- Mammograms were classified into four categories of density (MD), ACR-A, ACR-B, ACR-C, and ACR-D according to ACR BI-RADS atlas fifth edition 2013.

a. The breast are almost entirely fatty.

b. There are scattered areas of fibroglandular density. c. The breasts are heterogeneously dense.

d. The breasts are extremely dense.

- All radiological classifications were made using both standard CC and MLO views of both breasts.

\section{Results}

This study included 49,409 women outreached for screening by digital mammography from 2014 to 2019 . Their data were collected from the medical records of Kasereliny Hospital Radiology department.

The age in our study ranged between 40 and 65 years.

Among the collected cases, 11,569 were ACR-A (23\%), 24,135 were ACR-B (49\%), 12,250 were ACR-C (25\%), and 1455 were ACR-D (3\%) (Fig. 1).

One thousand five hundred cases of breast cancer were depicted radiologically and confirmed by histopathology.

Two hundred fifty breast cancer cases were detected in ACR-A class, 650 cases in ACR-B class, 400 cases in the ACR-C class, and 200 in the ACR-D class (Table 1).

The frequency of all the positive breast cancer cases in ACR-A density group was 2.2, ACR-B group was $2.7,3.3$ in ACR-C group, and 13.7 in ACR-D group (Fig. 2).

Densities were arranged in a descending order according to the frequency of positive cases:

\section{D (13.7\%), C (3.3\%), B (2.7\%), A (2.2\%)}

There was a significant increased risk of breast cancer with high breast densities collectively: ACR-C and ACRD (Fig. 3).

\section{Discussion}

There are many reasons behind the increasing rates of breast cancer in developing countries including Egypt; among these reasons is increasing breast density in women above age of 40 years [3]. So, in women over 40

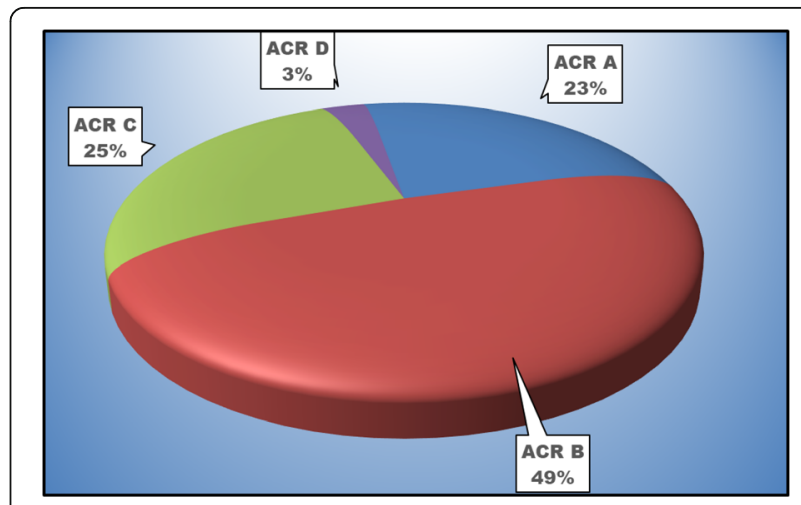

Fig. 1 Percentage distribution of ACR density among all studied cases 
Table 1 Breast density and increased breast cancer risk

\begin{tabular}{|c|c|c|c|c|c|c|c|c|}
\hline & \multicolumn{2}{|l|}{ ACR.A } & \multicolumn{2}{|l|}{ ACR.B } & \multicolumn{2}{|l|}{ ACR.C } & \multicolumn{2}{|l|}{ ACR.D } \\
\hline & Count & $\%$ & Count & $\%$ & Count & $\%$ & Count & $\%$ \\
\hline $\mathrm{Neg}$ & 11,319 & 97.8 & 23,485 & 97.3 & 11,850 & 96.7 & 1255 & 86.3 \\
\hline \multirow[t]{2}{*}{ Pos } & 250 & 2.2 & 650 & 2.7 & 400 & 3.3 & 200 & 13.7 \\
\hline & $A$ vs $B$ & $A$ vs $C$ & $A$ vs $D$ & B vs $C$ & B vs D & C vs D & & \\
\hline$p$ & 0.003 & 0 & 0 & 0.002 & 0 & 0 & & \\
\hline Sig. & HS & HS & HS & HS & HS & HS & & \\
\hline RRR & 1.2531 & 1.5283 & 7.2153 & 1.2196 & 5.7579 & 4.7211 & & \\
\hline $95 \mathrm{Cl}$ & $1.08-1.45$ & $1.30-1.79$ & $5.94-8.77$ & $1.07-1.38$ & $4.87-6.81$ & $3.95-5.65$ & & \\
\hline Risk & ACR B Pos.Sig. & ACR C Pos.Sig. & ACR D Pos.Sig. & ACR C Pos.Sig. & ACR D Pos.Sig. & ACR D Pos.Sig. & & \\
\hline
\end{tabular}

years of age, breast cancer remains one of the main reasons of death [4].

Increasing breast cancer survival rate with a possibility of complete cure is mostly the result of early detection that is why annual screening mammography is a must [5].

Annual screening for breast cancer is important in detecting women with asymptomatic breast cancer and as result better outcomes [1].

Mammogram films are usually a combination of both non-radiolucent areas and radiolucent areas representing a mixture of both fibroglandular tissue and fat, so ladies with increasing percent of fibroglandular tissue of $75 \%$ or more usually show more risk of developing breast cancer by 4 to 6 folds in comparison to those with increasing fatty component in mammogram [6].

Some of the studies used Wolfe classification instead of BI-RADS density classification in explaining the relation between the risk for breast density and breast cancer risk. Use of the BI-RADS classification has resulted in a similar but milder relation of risk with respect to breast density [7]. One study of the Vermont population from the BCSC registry that implied the BI-RADS density classifications stated that extremely dense breasts in women have increased breast cancer relative risk ratio in premenopausal than in post-menopausal females [8].

Ahmadinjad et al. showed that the occurrence of malignancy in dense breast patients $(61.2 \%)$ is more than in those with low breast densities $(37.3 \%)(P=0.007)$ as stated in our study that the frequency of breast cancer in groups ACR $C$ and ACR D is more than the frequency rate in groups ACR A and ACR B [9].

According to the BI-RADS edition 2013, cases were classified into the following: 11,569 were ACR-A (23\%), 24,135 were ACR-B (49\%), 12,250 were ACR-C (25\%), and 1455 were ACR-D (3\%).

Our study included 49,409 women, 1500 cases were pathologically proven with breast cancer out of the total. Out of the 1500 breast cancer cases, 250 were depicted in ACR-A class and 650 in ACR-B class, 400 cases in the ACR-C class, and 200 in the ACR-D class.

Cases were ordered in a descending pattern depending on the frequency of carcinoma positive cases:

D (13.7\%), C (3.3\%), B (2.7\%), A (2.2\%)

The positive relationship between increasing the risk of breast cancer in women with increasing breast mammographic density has been reported in many cohort studies [10]. Byrne et al. stated that women with breast

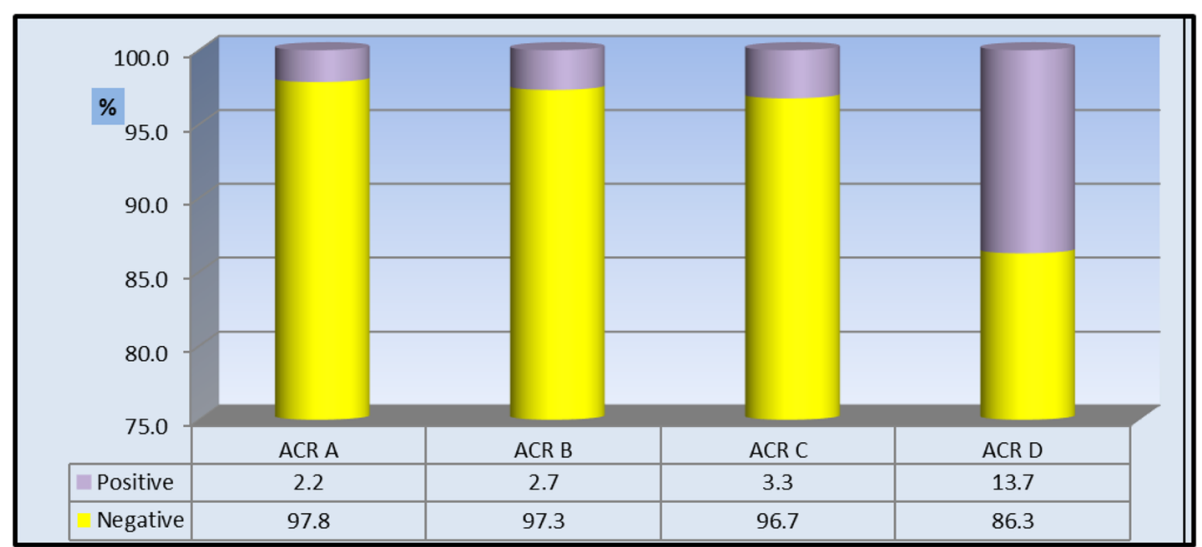

Fig. 2 Frequency of breast cancer as regards different mammographic densities 

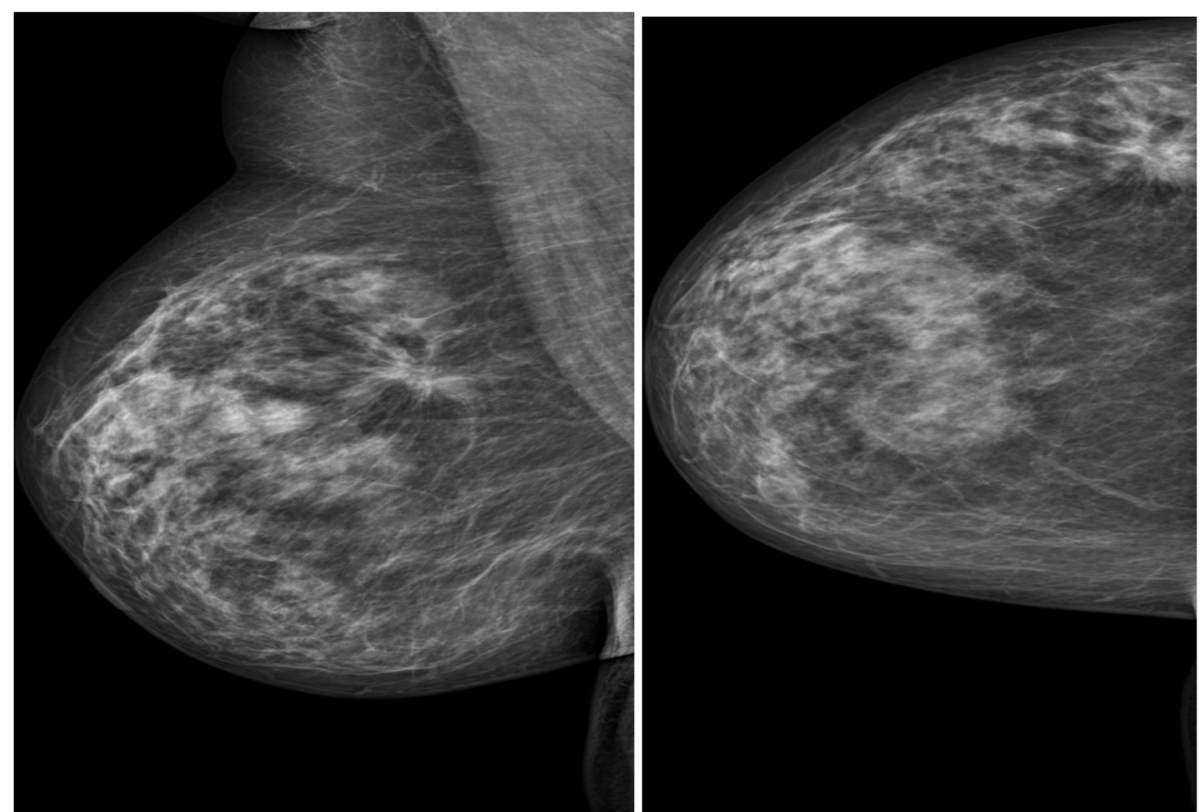

Fig. 3 Sixty-year-old female for screening ACR C. Right UOQ irregular shape speculated outline dense lesion

density of $75 \%$ or more showed four-fold increase in the risk affection with breast cancer than those with mammographic density of $0 \%$ [11].

As stated in our study, Maskarinec et al. also discovered that the risk for breast cancer affection increases by 3.6 times in women with breast density more than 50\% than women with density less than $10 \%$ [12].

Some studies reported that the relative cancer risk for breasts that were $50-74 \%$ dense was 2.92 and 4.64 for breasts that were $75 \%$ or more dense; as a result, there is a linear increasing trend between the relation of the breast cancer relative risk and increasing tissue breast density which was also reported in our study [7].

In our study, we found that women with ACR mammographic density class $D$ and $C$ have statistically increase frequency of positive carcinoma patients than class $\mathrm{A}$ and $\mathrm{B}$.

\section{Conclusion}

We finally concluded that there is a significant positive relation between increase in the risk of breast cancer in our population with increasing mammographic breast tissue density.

\section{Abbreviations}

ACR: American College of Radiology; MRI: Magnetic resonance imaging; BIRADS: Breast imaging-reporting and data system; MD: Mammographic density

\section{Acknowledgements}

First and foremost, thanks to Allah, the most beneficial and most merciful. It is but for His mercy that we can put through in life.

\section{Authors' contributions}

EA and MR analyzed and interpreted the patient data according to the mammographic examination and wrote the manuscript. All authors have read and approved the manuscript.

\section{Funding}

Not applicable.

\section{Availability of data and materials}

The data sets used and/or analyzed during the current study are available from the corresponding author on reasonable request.

\section{Declarations}

Ethics approval and consent to participate

The study is a prospective study that was reviewed by the ethics committee of radiology departments and was approved by the review board that is related to our University. Patients included gave informed written consent to use their data in research work. Reference number is not applicable.

\section{Consent for publication}

All the patients included in this research gave written informed consent to publish the data contained within this study.

\section{Competing interests}

The authors declare that they have no competing interests.

Received: 17 February 2021 Accepted: 19 April 2021

Published online: 17 May 2021

\section{References}

1. Mackenzie SF, Christoph IL, Joann GE (2015) Breast cancer screening an evidence-based update. Med Clin N Am 99(3):451-468

2. Martha BM, Ana L, Mary CM, Mary SN, Lisa B, Lora DB, D'Orsi C, Jennifer AH, Mary KH, Huynh PT, Peter MJ, Lee S-J, Constance DL, David AM, Joshua AN, Samir BP, Handel ER, Linda S, Bruce GH (2012) ACR Appropriateness Criteria Breast Cancer Screening

3. Jamal A, Center MM, DeSantis C and Ward EM (2010). Global patterns of cancer incidence and mortality rates and trends. Cancer Epidemiol Biomark Prev 19(8):1893-1907 
4. Yang T, Liang H, Chouc C, Huang J, Pan H (2013) Adjunctive digital breast tomosynthesis in diagnosis of breast cancer. Biomed Res Int 597253. https:// doi.org/10.11557/2013/597253

5. KöșüșN KA, Duran M, Simavlı S, Turhan N (2010) Comparison of standard mammography with digital mammography and digital infrared thermal imaging for breast cancer screening. Assoc. J Turk Ger Gynecol Assoc 11(3): 152-157

6. Tamimi RM, Byrne C, Colditz GA, Hankinson SE (2007) Endogenous hormone levels, mammographic density, and subsequent risk of breast cancer in postmenopausal women. J Natl Cancer Inst. 99(15):1178-1187. https://doi.org/10.1093/jnci/djm062

7. McCormack VA, dos Santos SI (2006) Breast density and parenchymal patterns as markers of breast cancer risk: a meta-analysis. Cancer Epidemio Biomarkers Prev 15(6):1159-1169. https://doi.org/10.1158/1055-9965.EPI-060034

8. Vacek PM, Geller BM (2004) A prospective study of breast cancer risk using routine mammographic breast density measurements. Cancer Epidemiol Biomarkers Prev 13(5):715-722

9. Ahmadinjad N, Movahedinia N, Shahriari M (2013) Iranian Red Crescent Med J 15(12):e16698

10. Boyd NF, Go H, Martin LJ, Sun L, Stone J, Fishell E et al (2007)

Mammographic density and the risk and detection of breast cancer. N Engl J Med 356(3):227-236. https://doi.org/10.1056/NEJMoa062790

11. Byrne C, Schairer C, Wolfe J, Parekh N, Salane M, Brinton LA, Hoover R, Haile $R$ (1995) Mammographic features and breast cancer risk: effects with time, age, and menopause status. J Natl Cancer Inst 87(21):1622-1629. https://doi. org/10.1093/jnci/87.21.1622

12. Maskarinec G, Pagano I, Lurie G, Wilkens LR, Kolonel LN (2005)

Mammoraphic density and breast cancer risk. Am J Epidemol 162(8):743752. https://doi.org/10.1093/aje/kwi270

\section{Publisher's Note}

Springer Nature remains neutral with regard to jurisdictional claims in published maps and institutional affiliations.

\section{Submit your manuscript to a SpringerOpen ${ }^{\circ}$ journal and benefit from:}

- Convenient online submission

- Rigorous peer review

- Open access: articles freely available online

- High visibility within the field

- Retaining the copyright to your article

Submit your next manuscript at $\boldsymbol{\nabla}$ springeropen.com 